http://jmscr.igmpublication.org/home/ ISSN (e)-2347-176x ISSN (p) 2455-0450

crossref DOI: https://dx.doi.org/10.18535/jmscr/v7i8.93

Journal Of Medical Science And Clinical Research

\title{
Perception of Clients on the Quality of Maternity Services Rendered in State Specialist Hospital Asubiaro, Osogbo
}

\author{
Authors \\ Oke Rebecca Oluwaseun, (MSc, PGDE, BNSc, RN, RM, RPHN, RME) ${ }^{1}$ \\ Oke Olufemi Sunday (FWCP, MPH, MBBS) ${ }^{2}$ \\ Dayo-Omole Adedolapo Adebukola, (MN, PGDE, BNSc, RN, RM, RPHN) ${ }^{3}$ \\ Ogidan, Oluwakemi Christie, (MSc, PGDE, BNSc, RN, RM, RPHN ${ }^{4}$
}

${ }^{1}$ Department of Nursing, Faculty of Basic Medical Sciences, College of Medicine, Ekiti State University, Ado-Ekiti

${ }^{2}$ Department of Community Medicine, LAUTECH Teaching Hospital, Ogbomoso

${ }^{3}$ Osun State School of Nursing, Asubiaro, Osogbo

${ }^{4}$ Department of Nursing, Faculty of Basic Medical Sciences, College of Medicine, Ekiti State University, Ado-Ekiti

\begin{abstract}
Background: Quality of Maternity Service is an important determinant of Safe Motherhood. The Ethiopia Demographic and Health Survey (EDHS) 2011 estimated maternal mortality rate to be 676 maternal deaths per 100,000 live births. Nigeria ranks second globally from maternal mortality rate. The aim of this study was to determine the Perception of clients on the quality of maternity services rendered in State Specialist Hospital Asubiaro, Osogbo.

Methods: A descriptive quantitative approach was used to obtain information relevant to the research question. 110 women who fulfilled the inclusion criteria were selected using purposive sampling technique. A structured questionnaire was administered to the respondent after they have consented to participate.

The completed questionnaire was retrieved and analyzed using SPSS version 17.0 with frequency tables and bar charts.
\end{abstract}

Findings: The finding revealed that more than half (59.1\%) of the clients perceived maternity services not to be of quality while only $40.9 \%$ perceived the services to be of quality.

They were most satisfied with the health care delivery (mean=23.01 \pm 2.03$)$, and least satisfied with the attitude of health care workers $(14.55 \pm 1.78)$. While most patients individually often desire longer consultation with care providers, they often expressed dissatisfaction with long waiting time. There was also greater preference for private health facilities to public health facilities and this was not due to difference in technical competence but primarily due to the process of service provision.

Conclusion and Recommendation: This study has provided an insight into an important, but often neglected aspect of maternal health care. This is necessary to improve on the current maternal health profile in the State Specialist Hospital, Asubiaro, Osogbo, Osun State, Nigeria. Overall, the findings of this study have demonstrated low level of satisfaction with the quality of maternity services rendered in this institution. We therefore recommend adequate staffing of health care facilities with skilled personnel, such as medical doctors and midwives. Policy makers should train public hospital staff on effective communication and interpersonal skills, more equipment should also be provided.

Keyword: Quality, Maternity Services, Pregnant Women, Nursing Mothers and Midwives. 


\section{Introduction}

Every day, approximately 830 women die from preventable causes related to pregnancy and childbirth, $99 \%$ of these maternal deaths occur in developing countries particularly sub-Saharan Africa (World Health Organization, 2018). Around the world, quality of care during antenatal intrapartum and postpartum period plays a vital role to promote maternal health, better birth process and a healthy baby. It was estimated that by the end of 2015, roughly 303,000 women will have died during and following pregnancy and childbirth, Almost all of these death occurred in low resource setting, and most could have been prevented (World Health Organization, 2017).

Maternal and child mortality is not an uncommon event in several parts of the developing world mother and children are at highest risk for disease and death. While motherhood is supposed to be a positive and fulfilling experience for women, it is associated with ill-health and even death for many (Mona, 2016). According to Ethiopia Demographic and Health Survey (EDHS) 2011, maternal mortality rate was estimated to be 676 maternal deaths per 100,000 live births (Tarekegn, Lieberman, Giedritis, 2014). However, in spite of the concentrated effort of the Ethiopian government, the level of maternal mortality is not reduced as desired.

Studies have shown that $99 \%$ of all maternal deaths occur in developing countries and it's higher in woman living in rural areas and among poorer communities. Young Adolescents face a higher risk of complications and death as a result of pregnancy than other women between 1990 and 2015, maternal mortality rate worldwide dropped by about $44 \%$ and this occur as result of skilled care before, during and after childbirth that save the lives of women and new-born babies (Prata, Passano, Sreenivas, Gerdts, 2010; Daughters of Africa, 2016).

Between 2016 and 2030, as part of the sustainable development Agenda, the target is to reduce the global maternal mortality ratio less than 70 per 100,000 live births. In sub-Saharan
Africa, a number of countries halved their level of maternal mortality since 1990. In other regions, including Asia and North Africa, even greater headway was made, studies also shows that most women who utilize antenatal care (ANC) service in sub-Saharan Africa (SSA) do not receive adequate attention, as care providers are overwhelmed by the number of pregnant women seeking ANC (Nikiema, Kameli, Capon, Sondo, Martin-Prevel, 2010). In the developing countries including Nigeria, standard of quality of care often sort by health managers and care providers. Although there are several policies and guidelines to ensure quality of care, the extent to which they are adhered to is not well known (Bauhoff, 2015). Despite successive efforts to improve maternal health outcomes in Nigeria, relevant indicators in the country remain generally poor. A woman's chance of dying during pregnancy and childbirth in Nigeria is high, at 1 in 13 as compared to 1 in 31 for sub-Saharan Africa (Izugbara, Wekesah, Adedini, 2016). Nigeria has high maternal and infant mortality partly contributed by the poor perception of patients concerning the quality of service making women patronize over the counter drugs instead of seeking care in public health care institution (Nnebue, Ebenebe, Adinma, Iyoke, Obionu \& Ilika, 2014). Although, In recent years the country embarked on measures to reform the healthcare system, including maternal healthcare (MHC) delivery in a bid to attain millennium development Goals (MDGS) 4 and 5.

In Nigeria, for instance, maternal mortality ratio increased from 545 to 575 deaths per 100,000 live births between 2008 and 2013, reflecting a worsening situation. Studies have shown that increased availability of service does not always translate to increased access to healthcare (National Population Commission (NPC), 2014; Federal Republic of Nigeria report on Millennium Development Goals (MDGs), 2010).

According to Emelumadu, et al,( 2014) many patients in south east Nigeria are poor and ignorant, hence often feel that they are not in a good position to influence the type and quality of 
service they recurs even if their expectation are not met. Therefore, quality of maternity service is a multidimensional concept and it refers to the standard of care that is regularly monitored by the nurse midwife.

\section{Methods and Procedures Design}

A quantitative descriptive cross sectional design was employed to determine the client perception on the quality of maternity services rendered in State Specialist Hospital Asubiaro, Osogbo.

\section{Recruitment of Participants}

Participants were recruited from the antenatal and postnatal clinic of the State Specialist Hospital. A simple random technique was used to recruit pregnant and nursing mothers assessing maternity services from the two clinics. The sample size was calculated to be 110 participants 70 pregnant women and 40 nursing mothers using Leslie Fiscer's Formula.

\section{Data collection}

A self-designed questionnaire based on the purpose of the study and extensive review of literature was used for data collection. The questionnaire consisted of 29 items and divided into four sections: socio-demographic characteristics, perception of client on the maternity services rendered at the State Specialist Hospital, Asubiaro, Osogbo, factors that can improve maternity services and barriers to the use of maternity services. The questionnaire was reviewed by the researchers and an expert in scale development to ensure the construct and content validity of the questionnaire. In order to ensure clarity and understanding of the items, the questionnaire was piloted among 6 pregnant women and 4 nursing mothers in similar settings in Osogbo. However, the data collected during the pre-test were not included in the actual study. The Cronbach's alpha of the present study was 0.67 .

Permission was sought from the director of nursing services of the hospital prior to data collection. The purpose of the study was explained to each participant. Participants who agreed to participate was administered the questionnaire for responses to be provided. A total of 150 questionnaires were distributed but 110 questionnaires were retrieved.

\section{Data analysis}

Data were analyzed using SPSS version 17.0 to conduct descriptive and correlational analysis. In order to examine the relationship between the socio-demographic characteristics and client's perception of quality of maternity services, Chi Square test was used to establish the relationship.

\section{Results}

Table 1: Socio-demographic characteristics of the respondents

\begin{tabular}{|c|c|c|}
\hline Variables & Frequency & Percentage \\
\hline $\begin{array}{l}\text { Age } \\
16-20 \\
21-25 \\
26-30 \\
31-35\end{array}$ & $\begin{array}{l}12 \\
21 \\
49 \\
28\end{array}$ & $\begin{array}{l}10.9 \\
19.1 \\
44.5 \\
25.5\end{array}$ \\
\hline $\begin{array}{l}\text { Religion } \\
\text { Islam } \\
\text { Christianity }\end{array}$ & $\begin{array}{l}52 \\
58\end{array}$ & $\begin{array}{l}47.3 \\
52.7\end{array}$ \\
\hline $\begin{array}{l}\text { Marital Status } \\
\text { Married } \\
\text { Single } \\
\text { Separated }\end{array}$ & $\begin{array}{c}72 \\
29 \\
9\end{array}$ & $\begin{array}{c}65.5 \\
26.4 \\
8.2\end{array}$ \\
\hline $\begin{array}{l}\text { Educational } \\
\text { Status } \\
\text { No education } \\
\text { Primary } \\
\text { Secondary } \\
\text { Tertiary }\end{array}$ & $\begin{array}{l}11 \\
14 \\
30 \\
55\end{array}$ & $\begin{array}{l}10.0 \\
12.7 \\
27.3 \\
50.0\end{array}$ \\
\hline $\begin{array}{l}\text { Occupation } \\
\text { Housewife } \\
\text { Trading } \\
\text { Civil servant }\end{array}$ & $\begin{array}{l}29 \\
49 \\
32\end{array}$ & $\begin{array}{l}26.4 \\
44.5 \\
29.1\end{array}$ \\
\hline $\begin{array}{l}\text { No of Children } \\
1-2 \\
3-4 \\
5 \text { and above }\end{array}$ & $\begin{array}{c}62 \\
44 \\
4\end{array}$ & $\begin{array}{c}56.4 \\
40.0 \\
3.6\end{array}$ \\
\hline
\end{tabular}

Table 1 shows the socio-demographic factors of the respondents with majority of them 49 (44.5\%) falls within the ages of 26-30 years and were married $(65.5 \%)$. More than half of the respondents $(52.7 \%)$ were Christians and $44.5 \%$ were Traders. 
Table 2: Mean and Standard Deviation of perception of Quality of Maternity Services

\begin{tabular}{|l|c|c|}
\hline Variable & Mean & $\begin{array}{c}\text { Standard } \\
\text { Deviation }\end{array}$ \\
\hline Health Facility & $\mathbf{1 9 . 3 7}$ & $\mathbf{3 . 5 0}$ \\
\hline Adequacy of Staff & 2.05 & 0.61 \\
\hline Adequacy of Room & 3.01 & 0.49 \\
\hline Adequacy of Water & 2.16 & 0.78 \\
\hline Clean Environment & 2.88 & 0.62 \\
\hline $\begin{array}{l}\text { Adequacy of } \\
\text { Equipment }\end{array}$ & 2.53 & 0.63 \\
\hline Distance & 2.78 & 0.11 \\
\hline Health Care Delivery & $\mathbf{2 3 . 0 1}$ & $\mathbf{2 . 0 3}$ \\
\hline Examine well & 2.88 & 0.35 \\
\hline Staff Competency & 3.13 & 0.37 \\
\hline Prescription of drug & 2.96 & 0.29 \\
\hline Cost of Service & 3.48 & 0.45 \\
\hline Availability of drugs & 2.07 & 0.52 \\
\hline Privacy & 2.76 & 0.53 \\
\hline Waiting time & 3.07 & 0.15 \\
\hline Adequacy of information & 2.85 & 0.52 \\
\hline Interpersonal Aspects & $\mathbf{1 4 . 5 5}$ & $\mathbf{1 . 7 8}$ \\
\hline Openness to clients & 2.81 & 0.46 \\
\hline Compassion for clients & 2.96 & 0.33 \\
\hline Respects for clients & 2.84 & 0.31 \\
\hline Time devoted to patients & 2.75 & 0.24 \\
\hline $\begin{array}{l}\text { Good interpersonal attitude to } \\
\text { clients }\end{array}$ & 2.18 & 0.11 \\
\hline
\end{tabular}

The quality of maternity services was assessed under 3 sub scales namely; Health facility, health care delivery and interpersonal aspect. With regards to health facility, adequate room, clean environment and distance from the community revealed high mean score of clients having good perception $(3.01 \pm 0.49,2.88 \pm 0.62$ and $2.78 \pm 0.11$ respectively). As regards health care delivery, staff competency, cost of service and waiting time revealed a High mean scores of clients having good perception $(3.13 \pm 0.37,3.48 \pm 0.44$ and $3.07 \pm 0.35$ respectively). Also, in the subscale of interpersonal aspects, respect for patient has highest mean score of 2.96 \pm 0.33 ; follow by compassion to patient and time devoted to clients having mean score of $2.91 \pm 0.46$ and $2.84 \pm 0.31$ respectively

Figure 1: Overall Perception of Respondents Irrespective of any Influence Factors

\section{Clients perception of quality of maternity services}

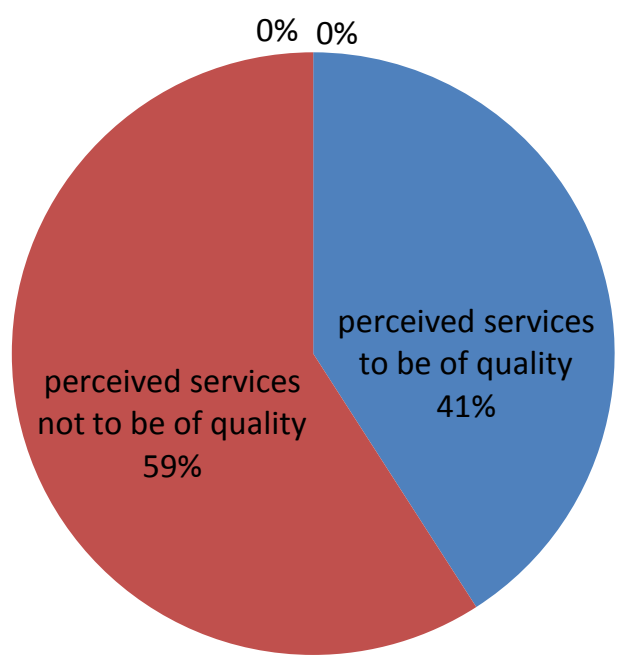

The Overall Perception of Respondents Irrespective of any Influence Factors is depicted in figure 1 . More than half $(59.1 \%)$ of the clients perceived maternity services not to be of quality while only $40.9 \%$ perceived the services to be of quality. 
Table 3: Socio-Demographic Characteristics and clients perception of quality of maternity services

\begin{tabular}{|l|c|c|c|c|c|}
\hline Variables & $\begin{array}{c}\text { Perceived } \\
\text { Services to be of } \\
\text { quality (\%) }\end{array}$ & $\begin{array}{c}\text { Perceived } \\
\text { services not to be } \\
\text { of quality (\%) }\end{array}$ & $\mathrm{X}^{2}$ & Df & P-Value \\
\hline Age(Years) & & & & & \\
\hline $16-25$ & $10(30.3)$ & $23(69.7)$ & 9.70 & 2 & 0.008 \\
\hline $26-35$ & $35(45.5)$ & $42(54.5)$ & & & \\
\hline Religion & & & & & \\
\hline Islam & $19(36.5)$ & $33(63.5)$ & 9.14 & 1 & 0.215 \\
\hline Christianity & $26(44.8)$ & $32(55.2)$ & & & \\
\hline Marital status & & & & & \\
\hline Married & $28(38.9)$ & $44(61.1)$ & 4.61 & 1 & 0.032 \\
\hline Single & $12(41.4)$ & $17(58.6)$ & & & \\
\hline Separated & $5(55.6)$ & $4(44.4)$ & & & \\
\hline Educational status & & & & & \\
\hline None & $4(36.4)$ & $7(63.6)$ & 3.83 & 2 & 0.147 \\
\hline Primary & $8(57.1)$ & $6(42.9)$ & & & \\
\hline Secondary & $11(36.7)$ & $19(63.6)$ & & & \\
\hline Tertiary & $22(40)$ & $33(60)$ & & & \\
\hline
\end{tabular}

Age $\left(X^{2}=9.70, \mathrm{df}=2, \mathrm{P}\right.$-value $\left.=0.008\right)$ and marital status $\left(\mathrm{X}^{2}=4.16, \quad \mathrm{df}=1, \quad \mathrm{P}\right.$-value $\left.=0.032\right) \quad$ were significantly associated with overall clients perception of quality of maternity services.

Table 4: The ways of improving the quality of maternity services as suggested by respondents

\begin{tabular}{|l|c|c|}
\hline $\begin{array}{l}\text { Factors that can help to improve } \\
\text { the quality of maternity services }\end{array}$ & Mean & SD \\
\hline $\begin{array}{l}\text { Adequate staffing of health care } \\
\text { facilities }\end{array}$ & 3.98 & 0.20 \\
\hline $\begin{array}{l}\text { Availability of equipment and } \\
\text { supplies }\end{array}$ & 3.76 & 0.15 \\
\hline Availability of services & 3.51 & 0.11 \\
\hline $\begin{array}{l}\text { Provision of essential drugs and } \\
\text { supplies }\end{array}$ & 2.86 & 1.21 \\
\hline $\begin{array}{l}\text { Provision of affordable care and } \\
\text { services }\end{array}$ & 2.11 & 0.89 \\
\hline $\begin{array}{l}\text { Positive and encouraging attitude } \\
\text { of health care providers }\end{array}$ & 2.71 & 0.16 \\
\hline
\end{tabular}

Most common suggestions for improving QMHCS include, adequate staffing of health care facilities with skilled personnel $(3.98 \pm 0.20)$, availability of equipment and supplies (3.76 \pm 0.15$)$ and availability of services $(3.51 \pm 0.11)$.

\section{Discussion}

Women utilizing maternity services are increasingly becoming aware and desirous of the need to improve quality of services provided to them. Their utilization of maternal care services has been shown to depend on their perceptions on these services (Vidler, et al. 2016). Hence, their perception of MHC services is an important measure for assessing the extent at which their expectations are being met by both the policy makers and the care providers. More than half $(59.1 \%)$ of the clients perceived maternity services not to be of quality while only $40.9 \%$ perceived the maternity services to be of quality. They were most satisfied with the health care delivery (mean=23.01 \pm 2.03 ), and least satisfied with the attitude of health care workers (14.55 \pm 1.78$)$. Elsewhere in Africa, clients' satisfaction with maternal services is generally high, even though service cost, payment mechanism and long waiting time were identified as barriers to $\mathrm{MH}$ service utilization (Emelumadu, et al., 2014). While most patients individually often desire longer consultation with care providers, they often expressed dissatisfaction with long waiting time. There was also greater preference for private health facilities to public health facilities and this was not due to difference in technical competence but primarily due to the process of service provision (Emelumadu, et al., 2014).

The most striking finding was client not satisfied with the attitude of health care workers (14.55 \pm 1.78$)$. It shows the importance women attach to being treated with courtesy and empathy, irrespective of socio-cultural or economic context. Women identify 'being treated as a human being' 
as one of the benchmarks of high quality care (Srivastava, Avan, Rajbangshi, Bhattacharyya, 2015). Across the world, women seek dignity and respect while undergoing maternity care. Provider behavior and attitudes are therefore major determinants of utilization of skilled maternity care. Increasing documentation of neglect and intentional abuse and humiliation of women during childbirth in countries across the world indicates that this is indeed a major factor inhibiting uptake of services (Srivastava, Avan, Rajbangshi, Bhattacharyya, 2015). In this context it is important that efforts to improve access and availability of skilled delivery care to women in developing countries focus equally on sensitizing providers on respectful care. Previous studies have not demonstrated consistent relationship between patient satisfaction and socio-demographic characteristics of users of healthcare services. This is because determinants of clients' satisfaction are multi-factorial and no factor has been shown to contribute to satisfaction or dissatisfaction more than the other. Patients' satisfaction with health services is purely individualistic and dynamic. On the contrary, more consistent association has been demonstrated between service satisfaction and age of patients. This study revealed that Age $\left(X^{2}=9.70, \quad d f=2, \quad P\right.$-value $\left.=0.008\right)$ and marital status $\left(X^{2}=4.16, \quad \mathrm{df}=1, \quad \mathrm{P}\right.$-value $\left.=0.032\right) \quad$ were significantly associated with overall clients perception of quality of maternity services.

\section{Conclusion}

This study has provided an insight into an important, but often neglected aspect of maternal health care. This is necessary to improve on the current maternal health profile in the State specialist hospital, Asubiaro, Osogbo, Osun State, Nigeria. Overall, the findings of this study have demonstrated low level of satisfaction with the quality of maternity services rendered in this institution. We therefore recommend adequate staffing of health care facilities with skilled personnel, such as medical doctors and midwives. Policy makers should train public hospital staff on effective communication and interpersonal skills, more equipment should also be provided.

\section{References}

1. Bauhoff, S. (2015) Improving Healthcare Quality: what can we learn from the US Experience. Center for Global Development.

2. Daughters of Africa (2106) Maternal Mortality. Retrieved from www.daughtersofafricablog.wordprss.com 2016/09/08 on $19 / 7 / 2019$

3. Emelumadu, O.F., Onyeonoro, U.U., Ukegbu, A.U., Ezeama, N.N., Ifeadike, C.O., Okezie, O.K. (2014) Perception of quality of maternal healthcare services among women utilizing antenatal services in selected primary health facilities in Anambra state, Southeast, Nigeria. Nigerian Medical Journal. 55(2):148-155

4. Federal Republic of Nigeria report on Millennium Development Goals (MDGs), (2010).

www.sparc-nigeria.com

5. Izugbara, C.O., Wekesah, F. M. \& Adedini, S. A. (2016) Maternal Health in Nigeria: A Situation Update. African Population and Health Research Center (APHRC), Nairobi, Kenya.

6. Mona, M. (2016) Major Causes of maternal mortality and morbidity. Nursing Exercise.

7. National Population Commission (NPC) [Nigeria] and ICF International (2014). Nigeria Demographic and Health Survey 2013. Abuja, Nigeria and Rockville, Maryland, USA: NPC and ICF International.

8. Nikiema, L., Kameli, YVES, Capon, G., Sondo, B., Martin-Prevel, YVES (2010). Quality of Antenatal care and Obstetrical coverage in rural Burkina Faso. Journal of Health Population and Nutrition. 28(1),6775. ISSN 1606-0997 
9. Nnebue, C.C., Ebenebe, U.E., Adinma, E.D., Iyoke, C.A., Obionu, C.N., Ilika, A.L. (2014) Client's Knowledge, Perception and Satisfaction with quality of maternal health care services at the primary health care level in Nnewi, Nigeria. Nigerian Journal of Clinical Practice. 17(5):594-601.

10. Prata, N., Passono, P., Sreenivas, A., Gerdts, C.E. (2010) Maternal mortality in developing countries: challenges in scaling up priority interventions. Women's Health. 6(2), 311-327.

11. Srivastava, A., Avan, B.I., Rajbangshi, P., Bhattacharyya, S. (2015) Determinants of women's satisfaction with maternal healthcare: A review of literature from developing countries. BMC Pregnancy Childbirth. 15:97

12. Tarekegn, S.M., Lieberman, L.S., Giedraitis, V. (2014) Determinants of Maternal health service utilization in Ethipia: Analysis of the 2011 Ethiopian Demographic and Health Survey (EDHS). BMC Pregnancy and Childbirth 14:161

13. Vidler, M., et al. (2016) Utilization of maternal health care services and their determinants in Karnataka state, India. BMC Reproductive Health. 13 suppl 1

14. World Health Organization, (2017) Maternal Mortality

15. World Health Organization, (2018) Maternal Health. 